\title{
FUZZY EXTENSION OF THE CODAS METHOD FOR MULTI-CRITERIA MARKET SEGMENT EVALUATION
}

\author{
Mehdi KESHAVARZ GHORABAEE ${ }^{1}$, Maghsoud AMIRI², \\ Edmundas Kazimieras ZAVADSKAS ${ }^{3}$, Reyhaneh HOOSHMAND ${ }^{4}$, \\ Jurgita ANTUCHEVIČIENE $\dot{E}^{5}$
}

1,2 Department of Industrial Management, Faculty of Management and Accounting, Allameh Tabataba'i University, Tehran, Iran

3, 5 Department of Construction Technology and Management, Faculty of Civil Engineering, Vilnius Gediminas Technical University, Sauletekio al. 11, 10223, Vilnius, Lithuania

${ }^{4}$ Department of Business Management, Faculty of Management and Accounting, Allameh Tabataba'i University, Tehran, Iran

E-mails:1m.keshavarz_gh@yahoo.com; 2amiri@atu.ac.ir;3edmundas.zavadskas@vgtu.lt;

4r.hooshmand.atu@gmail.com; 5jurgita.antucheviciene@vgtu.lt (correspondingauthor)

Received 28 November 2016; accepted 31 December 2016

\begin{abstract}
One of the important activities of a company that can increase its competitiveness is market segment evaluation and selection (MSE/MSS). We can usually consider MSE/MSS as a multi-criteria decision-making (MCDM) problem, and so we need to use an MCDM method to handle it. Uncertainty is one of the important factors that can affect the process of decision-making. Fuzzy MCDM approached have been designed to deal with the uncertainty of decision-making problems. In this study, a fuzzy extension of the CODAS (COmbinative Distance-based ASsessment) method is proposed to solve multi-criteria group decision-making problems. We use linguistic variables and trapezoidal fuzzy numbers to extend the CODAS method. The proposed fuzzy CODAS method is applied to an example of market segment evaluation and selection problem under uncertainty. To validate the results, a comparison is performed between the fuzzy CODAS and two other MCDM methods (fuzzy EDAS and fuzzy TOPSIS). A sensitivity analysis is also carried out to demonstrate the stability of the results of the fuzz CODAS. For this aim, ten sets of criteria weights are randomly generated and the example is solved using each set separately. The results of the comparison and the sensitivity analysis show that the proposed fuzzy CODAS method gives valid and stable results.
\end{abstract}

Keywords: market segment evaluation, market segment selection, MCDM, decisionmaking, fuzzy MCDM, fuzzy CODAS.

JEL Classification: D40, M30, D81, C44, C61. 


\section{Introduction}

Market segmentation becomes an essential element of marketing in industrial companies, since it helps to find homogeneous market segments and to expand company's market (Wedel, Kamakura 2012). The dividing process of a business market into some sub-groups of consumers, which are known as segments, is defined as market segmentation. In this definition, the business market can consist of existing and potential customers, and the segmentation is performed based on some characteristics which are common in the sub-groups. The resulted market segments are expected to have similar purchasing behavior (Dibb, Simkin 2008). Porter (2008) pointed out three generic types of strategies: cost leadership, differentiation and market segmentation which are usually used by diversified businesses to achieve competitive advantages. Geographic, demographic, psychographic, benefits sought and usage rate are some of different bases for market segmentation (Lamb et al. 2011). Montoya-Weiss and Calantone (1999) described four steps in the market segmentation process which include problem structuring, segment formation, segment evaluation and selection and description of segment strategy. After performing market segmentation, companies need to evaluate the resulted segments and select the most appropriate one(s). This evaluation and selection process can be considered as a critical managerial decision because it may affect other decisions related to marketing strategy (Wind, Thomas 1994). An overall review of academic researches indicates that existing studies have relatively neglected the process of market segment evaluation and selection.

Market segment evaluation and selection (MSE/MSS) problem usually involves some potential alternatives which need to be evaluated with respect to some potential criteria. Therefore, the MSE/MSS problem can be viewed as a multi-criteria decision-making (MCDM) problem. MCDM approaches are very useful in many disciplines of engineering and management such as transportation (Camargo Pérez et al. 2015; Barić et al. 2016), location selection (Kouchaksaraei et al. 2015; Ebrahimi, Mirzayi Modam 2016), tourism management (Hashemkhani Zolfani et al. 2015; Ranjan et al. 2016), supply chain management (Shahryari Nia et al. 2016), inventory management (Keshavarz Ghorabaee et al. 2015) and financial management (Shen, Tzeng 2016). Interested readers are referred to the recent review article about MCDM methods and their applications (Mardani et al. 2015), review of MCDM applications in transportation systems (Mardani et al. 2016) and developments of the TOPSIS method for decision-making problems (Zavadskas et al. 2016).

Some researchers have also studied on the application of MCDM methods in MSE/MSS problem. Dat et al. (2015) proposed an integrated MCDM method based on the quality function deployment (QFD) and TOPSIS (Technique for Order of Preference by Similarity to Ideal Solution) method for market segments evaluation and selection. Aghdaie and Alimardani (2015) presented a hybrid approach based on the AHP and TOPSIS methods for multi-criteria evaluation of market segments and validated in by using a case study. Mohammadi Nasrabadi et al. (2013) used the SPACE (Strategic Position \& ACtion Evaluation) and dynamic network process (DNP) to propose a modular deci- 
sion support system for MSE/MSS problem. In a research, Ou et al. (2009) developed a fuzzy MCDM approach for strategy-aligned market segment evaluation and selection. Based on the Porter's five forces model of competition (Porter 1979), which is depicted in Figure 1, Ou et al. (2009) presented the criteria and sub-criteria for evaluation and selection of market segments. Table 1 shows these criteria and sub-criteria which are used in the current study for evaluation process.

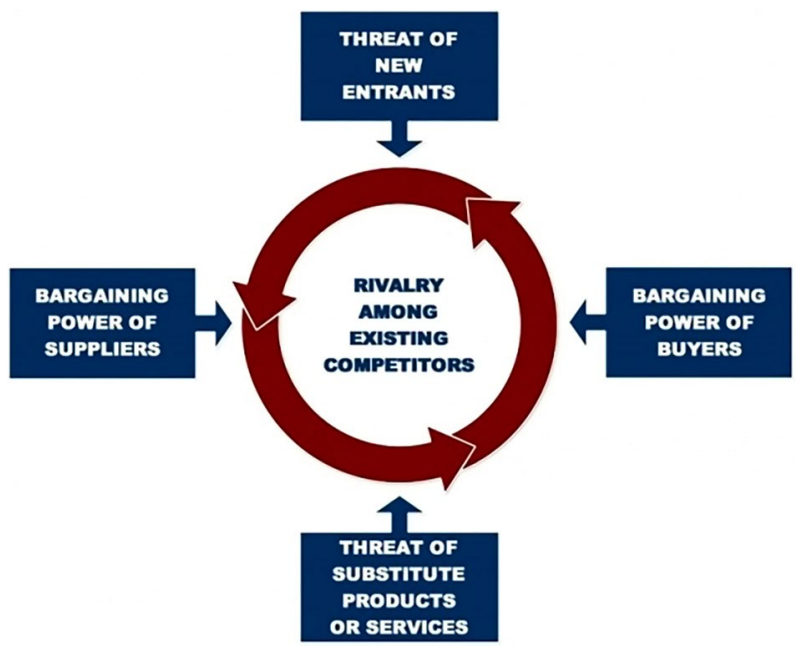

Fig. 1. Porter's five forces of competition

In the process of decision-making, we are usually confronted with uncertain information related to human thinking, judgment and reasoning. This type of uncertainty is usually handled by using the fuzzy sets theory in the MCDM problems. Many researchers have developed and applied some methods and techniques to deal with MCDM problems in fuzzy environments. Fuzzy TOPSIS method (Chen 2000), fuzzy AHP (Chang 1996), fuzzy VIKOR (VIseKriterijumska Optimizacija I Kompromisno Resenje) (Wang and Chang 2005), and fuzzy EDAS (Evaluation based on Distance from Average Solution) (Keshavarz Ghorabaee et al. 2016a) are some of extended MCDM methods in fuzzy environment. The fuzzy MCDM methods have been applied to many real-life problems (Aliakbari Nouri et al. 2015; Khandekar, Chakraborty 2015; Hosseini et al. 2016; Vinodh et al. 2016). Kahraman et al. (2015) performed a review on the fuzzy MCDM methods and their applications. We can see that some of the above mentioned studies on market segment evaluation and selection also utilized the fuzzy set theory to model the uncertainty of problem, and this fact shows the importance of using fuzzy MCDM approaches in MSE/MSS problems.

In this study, a fuzzy extension of the CODAS (COmbinative Distance-based ASsessment) method is developed to deal with multi-criteria decision-making problems in an uncertain environment. The CODAS methods is a new and efficient method which was proposed by Keshavarz Ghorabaee et al. (2016b). In the current research, we use the linguistic variables and trapezoidal fuzzy numbers to extend the CODAS method 
Table 1. Segment evaluation and selection criteria (Ou et al. 2009)

Criteria Sub-criteria

\begin{tabular}{|c|c|}
\hline \multirow{9}{*}{$\begin{array}{l}\text { The bargaining } \\
\text { power of } \\
\text { customers }\end{array}$} & Buyer concentration to firm concentration ratio \\
\hline & Bargaining leverage \\
\hline & Buyer volume \\
\hline & Buyer switching costs relative to firm switching costs \\
\hline & Buyer information availability \\
\hline & Ability to backward integrate \\
\hline & Availability of existing substitute products \\
\hline & Buyer price sensitivity \\
\hline & Price of total purchase \\
\hline \multirow{7}{*}{$\begin{array}{l}\text { The bargaining } \\
\text { power of } \\
\text { suppliers }\end{array}$} & Supplier switching costs relative to firm switching costs \\
\hline & Degree of differentiation of inputs \\
\hline & Presence of substitute inputs \\
\hline & Supplier concentration to firm concentration ratio \\
\hline & $\begin{array}{l}\text { Threat of forward integration by suppliers relative to the threat of backward } \\
\text { integration by firms }\end{array}$ \\
\hline & Cost of inputs relative to selling price of the product \\
\hline & Importance of volume to supplier \\
\hline \multirow{9}{*}{$\begin{array}{l}\text { The threat of } \\
\text { new entrants }\end{array}$} & The existence of barriers to entry \\
\hline & Economies of product differences \\
\hline & Brand equity \\
\hline & Switching costs \\
\hline & Capital requirements \\
\hline & Expected retaliation \\
\hline & Absolute cost advantages \\
\hline & Learning curve advantages \\
\hline & Government policies \\
\hline \multirow{4}{*}{$\begin{array}{l}\text { The threat } \\
\text { of substitute } \\
\text { products }\end{array}$} & Buyer propensity to substitute \\
\hline & Relative price performance of substitutes \\
\hline & Buyer switching costs \\
\hline & Perceived level of product differentiation \\
\hline \multirow{8}{*}{$\begin{array}{l}\text { The intensity } \\
\text { of competitive } \\
\text { rivalry }\end{array}$} & Number of competitors \\
\hline & Rate of industry growth \\
\hline & Intermittent industry overcapacity \\
\hline & Exit barriers \\
\hline & Diversity of competitors \\
\hline & Informational complexity and asymmetry \\
\hline & Fixed cost allocation per value added \\
\hline & Level of advertising expense \\
\hline
\end{tabular}


and propose a multi-criteria group decision-making approach. A numerical example of a shoe company is utilized to show the applicability of the fuzzy CODAS method in multi-criteria market segment evaluation and selection. For validating the proposed method, we compare the results with the results of the fuzzy EDAS and fuzzy TOPSIS methods. A sensitivity analysis is also performed to demonstrate the stability of the ranking results of the fuzzy CODAS method.

The rest of this paper is organized as follows. In Section 1, some basic concepts and definitions of fuzzy sets and fuzzy numbers are presented. In Section 2, an extension of the CODAS method is proposed to handle fuzzy multi-criteria group decision-making. Then the proposed fuzzy CODAS method is applied to an example of multi-criteria evaluation of market segments in Section 3. In this section, we also perform a comparison and a sensitivity analysis to demonstrate the validity and stability of the results. Sensitivity analysis results are discussed in Section 4. Finally, the conclusions are presented.

\section{Preliminaries}

The fuzzy sets theory, which was proposed by Zadeh (1965), is the most efficient tool to handle the uncertainty in many real-life problems and different disciplines of science and engineering. Fuzzy logic provides an inference morphology that enables approximate human reasoning capabilities to be applied to knowledge-based systems. The theory of fuzzy sets provides a mathematical tool to capture the uncertainties associated with human cognitive processes, such as thinking and reasoning. Multi- criteria decision-making is one of the important processes that involve human thinking and reasoning. Thus the theory of fuzzy sets could be very useful to model the uncertainty of MCDM problems. In the following, we present some definitions related to this theory. Definition 1. In a universal set $X$, a fuzzy subset $\tilde{M}$ is defined by a membership function $\mu_{\tilde{M}} x$ ) as follows (Zimmermann 2010):

$$
\tilde{M}=\left\{\left(x, \mu_{\tilde{M}}(x)\right) \mid x \in X\right\},
$$

where $x \in X$ denotes the elements belonging to the universal set, and $\mu_{\tilde{M}}(x): X \rightarrow[0,1]$.

Definition 2. A fuzzy number is a special case of a convex, normalized fuzzy subset $\left.\left(\sup \mu_{\tilde{M}} x\right)=1\right)$ of the real line $\left.\mathbb{R}\left(\mu_{\tilde{M}} x\right): \mathbb{R} \rightarrow[0,1]\right)$ (Wang, Lee 2007).

Definition 3. If the membership function of a fuzzy number $\tilde{M}$ follows the following form, it is called the trapezoidal fuzzy number (Ölçer, Odabaşi 2005):

$$
\left.\mu_{\tilde{M}} \quad x\right)=\left\{\begin{array}{lc}
\left(x-m_{1}\right) /\left(m_{2}-m_{1}\right), & m_{1} \leq x \leq m_{2} \\
1, & m_{2} \leq x \leq m_{3} \\
\left(m_{4}-x\right) /\left(m_{4}-m_{3}\right), & m_{3} \leq x \leq m_{4} \\
0, & \text { otherwise }
\end{array} .\right.
$$

A quadruplet $\tilde{M}=\left(m_{1}, m_{2}, m_{3}, m_{4}\right)$ can also be used to define this fuzzy number. Figure 2 shows an example of this type of fuzzy numbers. 


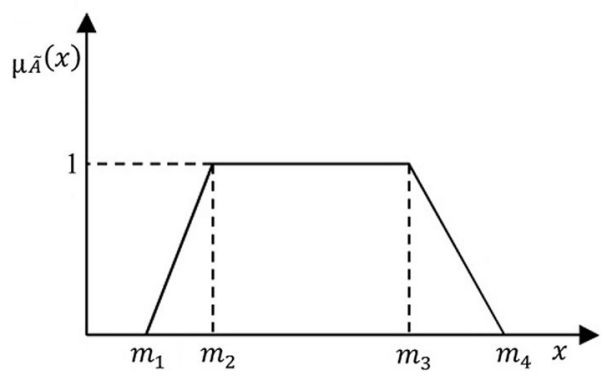

Fig. 2. Trapezoidal fuzzy number

Definition 4. Suppose that $k$ is a crisp number. The arithmetic operations of two positive trapezoidal fuzzy numbers $\tilde{M}=\left(m_{1}, m_{2}, m_{3}, m_{4}\right)$ and $\tilde{N}=\left(n_{1}, n_{2}, n_{3}, n_{4}\right)$ where $m_{1} \geq 0$ and $n_{1} \geq 0$ are defined as follows (Chen, Hwang 1992):

- Addition:

$$
\begin{gathered}
\tilde{M} \oplus \tilde{N}=\left(m_{1}+n_{1}, m_{2}+n_{2}, m_{3}+n_{3}, m_{4}+m_{4}\right) ; \\
\tilde{M}+k=\left(m_{1}+k, m_{2}+k, m_{3}+k, m_{4}+k\right) .
\end{gathered}
$$

- Subtraction:

$$
\begin{gathered}
\tilde{M} \odot \tilde{N}=\left(m_{1}-n_{4}, m_{2}-n_{3}, m_{3}-n_{2}, m_{4}-n_{1}\right) ; \\
\tilde{M}-k=\left(m_{1}-k, m_{2}-k, m_{3}-k, m_{4}-k\right) .
\end{gathered}
$$

- Multiplication:

$$
\begin{gathered}
\tilde{M} \otimes \tilde{N}=\left(m_{1} \times n_{1}, m_{2} \times n_{2}, m_{3} \times n_{3}, m_{4} \times n_{4}\right) ; \\
\tilde{M} \times k=\left\{\begin{array}{lll}
\left(m_{1} \times k, m_{2} \times k, m_{3} \times k, m_{4} \times k\right) & \text { if } \quad k \geq 0 \\
\left(m_{4} \times k, m_{3} \times k, m_{2} \times k, m_{1} \times k\right) & \text { if } & k<0
\end{array} .\right.
\end{gathered}
$$

- Division:

$$
\begin{gathered}
\tilde{M} \oslash \tilde{M}=\left(m_{1} / n_{4}, m_{2} / m_{3}, m_{3} / n_{2}, m_{4} / n_{1}\right) ; \\
\tilde{M} / k=\left\{\begin{array}{lll}
\left(m_{1} / k, m_{2} / k, m_{3} / k, m_{4} / k\right) & \text { if } & k>0 \\
\left(m_{4} / k, m_{3} / k, m_{2} / k, m_{1} / k\right) & \text { if } & k<0
\end{array} .\right.
\end{gathered}
$$

Definition 5. The defuzzified (crisp) value of a fuzzy number $\tilde{M}=\left(m_{1}, m_{2}, m_{3}, m_{4}\right)$ is defined as follows (Wang et al. 2006):

$$
\mathfrak{D}(\tilde{A})=\frac{1}{3}\left(m_{1}+m_{2}+m_{3}+m_{4}-\frac{m_{3} m_{4}-m_{1} m_{2}}{\left(m_{3}+m_{4}\right)-\left(m_{1}+m_{2}\right)}\right) .
$$

Definition 6. The weighted Euclidean $\left(d_{E}\right)$ and weighted Hamming $\left(d_{H}\right)$ distances between two trapezoidal fuzzy numbers $\tilde{M}=\left(m_{1}, m_{2}, m_{3}, m_{4}\right)$ and $\tilde{N}=\left(n_{1}, n_{2}, n_{3}, n_{4}\right)$ are defined as follows (Li 2007):

$$
d_{E}(\tilde{M}, \tilde{N})=\sqrt{\frac{\left(m_{1}-n_{1}\right)^{2}+2\left(m_{2}-n_{2}\right)^{2}+2\left(m_{3}-n_{3}\right)^{2}+\left(m_{4}-n_{4}\right)^{2}}{6}}
$$




$$
d_{H}(\tilde{M}, \tilde{N})=\frac{\left|m_{1}-n_{1}\right|+2\left|m_{2}-n_{2}\right|+2\left|m_{3}-n_{3}\right|+\left|m_{4}-n_{4}\right|}{6}
$$

\section{Fuzzy CODAS method}

In this section, we propose a fuzzy extension of the CODAS method to deal with multicriteria decision-making problems. As previously stated, the CODAS method is a new and efficient MCDM method which introduced by Keshavarz Ghorabaee et al. (2016b) recently. The desirability of alternatives in the CODAS method is determined based on $l^{1}$-norm and $l^{2}$-norm indifference spaces for criteria. According to these spaces, in the procedure of this method, a combinative form of the Euclidean and Taxicab distances is utilized for calculation of the assessment score of alternatives. However, the Euclidean and Taxicab distances are defined in a crisp environment and we cannot use them in fuzzy problems. The aim of this study is to develop a fuzzy extension of the CODAS method. In order to reach this aim, we use the fuzzy weighted Euclidean distance and fuzzy weighted Hamming distance, which were presented by Li (2007) (Definition 6), instead of the crisp distances. Suppose that we have $n$ alternatives and $m$ criteria and $q$ decision-makers (DMs). The steps of the fuzzy CODAS method for multi-criteria group decision-making are presented as follows:

Step 1. Construct the fuzzy decision matrix $\left(\tilde{X}_{l}\right)$ of each decision-maker and compute the average fuzzy decision matrix $(\tilde{X})$ as follows:

$$
\begin{gathered}
\tilde{X}_{l}=\left[\tilde{x}_{i j l}\right]_{n \times m}=\left[\begin{array}{cccc}
\tilde{x}_{11 l} & \tilde{x}_{12 l} & \cdots & \tilde{x}_{1 m l} \\
\tilde{x}_{21 l} & \tilde{x}_{22 l} & \cdots & \tilde{x}_{2 m l} \\
\vdots & \vdots & \vdots & \vdots \\
\tilde{x}_{n 1 l} & \tilde{x}_{n 2 l} & \cdots & \tilde{x}_{n m l}
\end{array}\right] ; \\
\tilde{X}=\left[\tilde{x}_{i j}\right]_{n \times m}=\left[\begin{array}{cccc} 
& & & \\
\tilde{x}_{11} & \tilde{x}_{12} & \cdots & \tilde{x}_{1 m} \\
\tilde{x}_{21} & \tilde{x}_{22} & \cdots & \tilde{x}_{2 m} \\
\vdots & \vdots & \vdots & \vdots \\
\tilde{x}_{n 1} & \tilde{x}_{n 2} & \cdots & \tilde{x}_{n m}
\end{array}\right] ; \\
q \\
\tilde{x}_{i j}= \\
\oplus \tilde{x}_{i j l},
\end{gathered}
$$

where $\tilde{x}_{i j l}$ denotes the fuzzy performance value of $i$ th $\left.(i \in 1,2, \ldots, n\}\right)$ alternative with respect to $j$ th criterion $(j \in\{1,2, \ldots, m\})$ and $l$ th $(l \in 1,2, \ldots, q\})$ decision-maker, and $\tilde{x}_{i j}$ shows the average fuzzy performance value of $i$ th alternative with respect to $j$ th criterion. 
Step 2. Obtain the fuzzy weight of each criterion from each decision-maker and calculate average fuzzy weights as follows:

$$
\begin{gathered}
\tilde{W}_{l}=\left[\tilde{w}_{j l}\right]_{1 \times m} ; \\
\tilde{W}=\left[\tilde{w}_{j}\right]_{1 \times m} ; \\
q \\
\tilde{w}_{j}=\oplus \tilde{w}_{j l}, \\
l=1
\end{gathered}
$$

where $\tilde{w}_{j l}$ denotes the fuzzy weight of $j$ th criterion $(j \in\{1,2, \ldots, m\})$ with respect to $l$ th $(l \in\{1,2, \ldots, q\})$ decision-maker, and $\tilde{w}_{j}$ shows the average fuzzy weight of $j$ th criterion.

Step 3. Determine fuzzy normalized decision matrix according to the type of each criterion using the following equations:

$$
\begin{gathered}
\tilde{N}=\left[\tilde{n}_{i j}\right]_{n \times m} ; \\
\tilde{n}_{i j}=\left\{\begin{array}{ll}
\tilde{x}_{i j} / \max _{i} \mathfrak{D}\left(\tilde{x}_{i j}\right) & \text { if } j \in B \\
1-\left(\tilde{x}_{i j} / \max _{i} \mathfrak{D}\left(\tilde{x}_{i j}\right)\right) & \text { if } j \in C
\end{array},\right.
\end{gathered}
$$

where $B$ and $C$ represent the sets of benefit and cost criteria, respectively, and $\tilde{n}_{i j}$ denotes the normalized fuzzy performance values.

Step 4. Calculate fuzzy weighted normalized decision matrix. The fuzzy weighted normalized performance values $\left(\tilde{r}_{i j}\right)$ are calculated as follows:

$$
\begin{gathered}
\tilde{R}=\left[\tilde{r}_{i j}\right]_{n \times m} ; \\
\tilde{r}_{i j}=\tilde{w}_{j} \otimes \tilde{n}_{i j},
\end{gathered}
$$

where $\tilde{w}_{j}$ denotes the fuzzy weight of $j$ th criterion, and $0<\mathfrak{D}\left(\tilde{w}_{j}\right)<1$.

Step 5. Determine fuzzy negative-ideal solution as follows:

$$
\begin{gathered}
\widetilde{N S}=\left[\widetilde{n S}_{j}\right]_{1 \times m} ; \\
\widetilde{n s} j=\min _{i} \tilde{r}_{i j},
\end{gathered}
$$

where $\min _{i} \tilde{r}_{i j}=\left\{\tilde{r}_{k j} \mid \mathfrak{D}\left(\tilde{r}_{k j}\right)=\min _{i}\left(\mathfrak{D}\left(\tilde{r}_{i j}\right)\right), k \in\{1,2, \ldots, n\}\right\}$.

Step 6. Calculate the fuzzy weighted Euclidean $\left(E D_{i}\right)$ and fuzzy weighted Hamming $\left(H D_{i}\right)$ distances of alternatives from the fuzzy negative-ideal solution, shown as follows:

$$
E D_{i}=\sum_{j=1}^{m} d_{E}\left(\tilde{r}_{i j}, \widetilde{n s}_{j}\right)
$$




$$
H D_{i}=\sum_{j=1}^{m} d_{H}\left(\tilde{r}_{i j}, \widetilde{n s}_{j}\right) .
$$

Step 7. Determine relative assessment matrix $(R A)$, shown as follows:

$$
\begin{gathered}
R A=\left[p_{i k}\right]_{n \times n} ; \\
p_{i k}=\left(E D_{i}-E D_{k}\right)+\left(t\left(E D_{i}-E D_{k}\right) \times\left(H D_{i}-H D_{k}\right)\right),
\end{gathered}
$$

where $k \in\{1,2, \ldots, n\}$ and $t$ is a threshold function that is defined as follows:

$$
t(x)=\left\{\begin{array}{lll}
1 & \text { if } & |x| \geq \theta \\
0 & \text { if } & |x|<\theta
\end{array} .\right.
$$

The threshold parameter $(\theta)$ of this function can be set by decision-maker. In this study, we use $\theta=0.02$ for the calculations.

Step 8. Calculate the assessment score $\left(A S_{i}\right)$ of each alternative, shown as follows:

$$
A S_{i}=\sum_{k=1}^{n} p_{i k} .
$$

Step 9. According to the decreasing values of assessment scores, we can rank the alternatives. The alternative with the highest assessment score is the most desirable alternative.

\section{Application of the fuzzy CODAS in MSS/MSE}

In this section, we use an example of multi-criteria strategy-aligned market segment evaluation to show the applicability of the proposed fuzzy CODAS method. The example is related to a shoe company which decides to expand its market. The company needs to evaluate some potential market segments and select the most appropriate of them for future investment. In the first step, the executive director and general manager of the company made an initial evaluation on some potential market segments based on their expected profitability and reached five market segments $\left(S_{1}\right.$ to $\left.S_{5}\right)$ for further evaluation. They formed a group of five experts $\left(D_{1}\right.$ to $\left.D_{5}\right)$, which we call decisionmaking group, including marketing manager, financial manager, purchasing manager, customer service manager and research and development manager to perform the final evaluation. Then the decision-making group selected the most important evaluation criteria (sub-criteria) according to the criteria defined by Ou et al. (2009) and shown in Table 1. The hierarchical structure of the problem is represented in Figure 3. As can be seen in this figure, we have five alternatives that need to be evaluated with respect to sixteen criteria. To make this evaluation, the decision-makers express their assessments using linguistic variables. The linguistic variables for weighting criteria and the linguistics variables for rating alternatives are shown in Table 2. In the following, the steps of using the proposed fuzzy CODAS method for the evaluation of market segments are presented: 


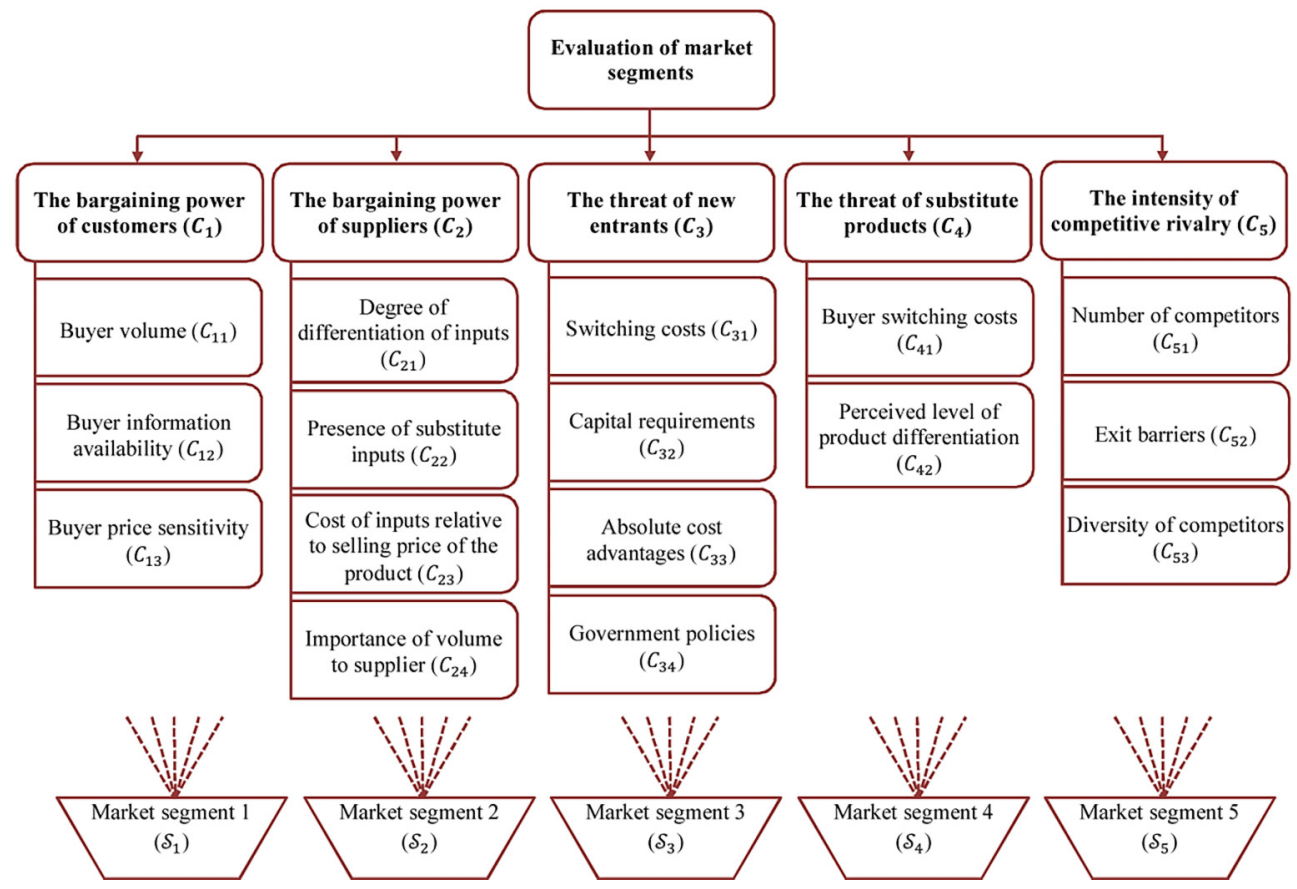

Fig. 3. Hierarchical structure of the problem

Table 2. Linguistic variables and their fuzzy numbers

\begin{tabular}{|c|c|c|}
\hline Usage & Linguistic variable & Trapezoidal fuzzy number \\
\hline \multirow{7}{*}{ For weighting criteria } & Very low (VL) & $(0,0,0.1,0.2)$ \\
\hline & Low (L) & $(0.1,0.2,0.2,0.3)$ \\
\hline & Medium low (ML) & $(0.2,0.3,0.4,0.5)$ \\
\hline & Medium (M) & $(0.4,0.5,0.5,0.6)$ \\
\hline & Medium high (MH) & $(0.5,0.6,0.7,0.8)$ \\
\hline & High $(\mathrm{H})$ & $(0.7,0.8,0.8,0.9)$ \\
\hline & Very high $(\mathrm{VH})$ & $(0.8,0.9,1,1)$ \\
\hline \multirow{7}{*}{ For rating alternatives } & Very poor (VP) & $(0,0,1,2)$ \\
\hline & Poor $(\mathrm{P})$ & $(1,2,2,3)$ \\
\hline & Medium poor (MP) & $(2,3,4,5)$ \\
\hline & Fair $(\mathrm{F})$ & $(4,5,5,6)$ \\
\hline & Medium good (MG) & $(5,6,7,8)$ \\
\hline & Good $(G)$ & $(7,8,8,9)$ \\
\hline & Very good (VG) & $(8,9,10,10)$ \\
\hline
\end{tabular}


Step 1. The decision-makers expressed their assessments of alternatives on each criterion using the linguistic variables presented in Table 2. The assessments of decisionmakers (decision matrix of each DM) are shown in Table 3. Based on this table and Eqs. (14) to (16) the average fuzzy decision matrix is calculated. The results are shown in Table 4.

Table 3. Ratings of the alternatives on each criterion by each DM

\begin{tabular}{|c|c|c|c|c|c|c|c|c|c|c|c|c|c|c|c|c|c|}
\hline & & $C_{11}$ & $C_{12}$ & $C_{13}$ & $C_{21}$ & $C_{22}$ & $C_{23}$ & $C_{24}$ & $C_{31}$ & $C_{32}$ & $C_{33}$ & $C_{34}$ & $C_{41}$ & $C_{42}$ & $C_{51}$ & $C_{52}$ & $C_{53}$ \\
\hline & $S_{1}$ & $\mathrm{P}$ & G & MP & G & $\mathrm{F}$ & MG & VP & F & VG & G & $\mathrm{F}$ & MG & G & $\mathrm{P}$ & VG & $\mathrm{F}$ \\
\hline & $S_{2}$ & $\mathrm{P}$ & G & $\mathrm{F}$ & VG & $\mathrm{F}$ & $\mathrm{F}$ & $\mathrm{P}$ & MP & G & MG & $\mathrm{F}$ & $\mathrm{F}$ & G & $\mathrm{P}$ & G & $\mathrm{G}$ \\
\hline \multirow[t]{5}{*}{$D_{1}$} & $S_{3}$ & $\mathrm{VP}$ & $\mathrm{MG}$ & $\mathrm{F}$ & $\mathrm{VG}$ & $\mathrm{MG}$ & G & VP & MP & VG & G & MP & MG & F & MP & G & G \\
\hline & $S_{4}$ & MP & MG & MP & G & MG & G & $\mathrm{P}$ & F & VG & G & $\mathrm{F}$ & MG & MG & MP & VG & VG \\
\hline & $S_{5}$ & $\mathrm{P}$ & $\mathrm{MG}$ & $\mathrm{F}$ & $\mathrm{MG}$ & $\mathrm{F}$ & $\mathrm{MG}$ & MP & MP & G & $\mathrm{MG}$ & MP & $\mathrm{F}$ & $\mathrm{F}$ & $\mathrm{F}$ & $\mathrm{MG}$ & $\mathrm{VG}$ \\
\hline & $S_{1}$ & $F$ & $\mathrm{G}$ & $\mathrm{F}$ & G & MG & MP & MP & G & $\mathrm{VG}$ & G & $\mathrm{F}$ & MP & $\mathrm{VG}$ & MG & $\mathrm{P}$ & $\mathrm{F}$ \\
\hline & $S_{2}$ & $\mathrm{~F}$ & G & MP & VG & MG & $\mathrm{F}$ & P & VG & VG & MG & $\mathrm{F}$ & F & G & MG & $\mathrm{P}$ & MG \\
\hline \multirow[t]{5}{*}{$D_{2}$} & $S_{3}$ & $\mathrm{MG}$ & $\mathrm{VG}$ & $\mathrm{F}$ & $\mathrm{G}$ & G & $\mathrm{F}$ & $\mathrm{VP}$ & G & $\mathrm{G}$ & $\mathrm{MG}$ & $\mathrm{MG}$ & $\mathrm{F}$ & G & G & $\mathrm{MP}$ & $F$ \\
\hline & $S_{4}$ & MG & VG & MP & $\mathrm{G}$ & MG & F & VP & $\mathrm{VG}$ & VG & MG & $\mathrm{F}$ & MP & $\mathrm{MG}$ & G & $\mathrm{P}$ & $\mathrm{MG}$ \\
\hline & $S_{5}$ & $\mathrm{~F}$ & G & $\mathrm{F}$ & $\mathrm{MG}$ & G & MP & MP & $\mathrm{G}$ & $\mathrm{G}$ & $F$ & $\mathrm{MG}$ & $\mathrm{F}$ & $\mathrm{MG}$ & $\mathrm{MG}$ & MP & $\mathrm{G}$ \\
\hline & $S_{1}$ & T & $\mathrm{F}$ & VP & MG & $\mathrm{P}$ & $\mathrm{VP}$ & $\mathrm{G}$ & MP & $\mathrm{P}$ & MG & MP & $\mathrm{F}$ & $\mathrm{G}$ & $\mathrm{F}$ & $V P$ & $\mathrm{~F}$ \\
\hline & $S_{2}$ & VP & MG & $\mathrm{P}$ & G & MP & VP & MG & $\mathrm{F}$ & MP & MG & VP & MG & MG & MP & VP & $\mathrm{MG}$ \\
\hline \multirow[t]{5}{*}{$D_{3}$} & $S_{3}$ & $\mathrm{P}$ & $\mathrm{F}$ & $P$ & $\mathrm{~F}$ & $\mathrm{~F}$ & $\mathrm{P}$ & $\mathrm{F}$ & $\mathrm{F}$ & MP & $\mathrm{F}$ & $\mathrm{P}$ & $\mathrm{F}$ & $\mathrm{MG}$ & MP & $\mathrm{P}$ & $\mathrm{F}$ \\
\hline & $S_{4}$ & MP & $\mathrm{F}$ & MP & $\mathrm{G}$ & MP & $\mathrm{P}$ & $\mathrm{F}$ & MP & $\mathrm{P}$ & $\mathrm{MG}$ & MP & F & $\mathrm{F}$ & $\mathrm{P}$ & $\mathrm{P}$ & $\mathrm{F}$ \\
\hline & $S_{5}$ & $\mathrm{P}$ & $\mathrm{F}$ & VP & $\mathrm{F}$ & $\mathrm{P}$ & VP & MG & $\mathrm{F}$ & $P$ & $F$ & $\mathrm{P}$ & MP & $\mathrm{F}$ & $\mathrm{F}$ & $\mathrm{VP}$ & $\mathrm{MG}$ \\
\hline & $S_{1}$ & $\mathrm{VG}$ & G & G & $\mathrm{MG}$ & $P$ & $\mathrm{VG}$ & $\mathrm{F}$ & $\mathrm{G}$ & $\mathrm{VG}$ & $\mathrm{F}$ & MP & $\mathrm{G}$ & $\mathrm{F}$ & $\mathrm{VG}$ & $\mathrm{F}$ & $\mathrm{MG}$ \\
\hline & $S_{2}$ & $\mathrm{VG}$ & $\mathrm{MG}$ & $\mathrm{VG}$ & $\mathrm{MG}$ & MP & $\mathrm{VG}$ & $F$ & $\mathrm{G}$ & $\bar{G}$ & $F$ & $\mathrm{~F}$ & $\Gamma$ & G & $\mathrm{VG}$ & MP & $\mathrm{MG}$ \\
\hline \multirow[t]{5}{*}{$D_{4}$} & $S_{3}$ & G & $\mathrm{MG}$ & $\mathrm{VG}$ & $\mathrm{F}$ & $\mathrm{F}$ & $\mathrm{G}$ & $\mathrm{MG}$ & $\mathrm{VG}$ & $\mathrm{MG}$ & $\mathrm{MG}$ & $\mathrm{F}$ & $\mathrm{F}$ & $\mathrm{F}$ & G & MP & $\mathrm{G}$ \\
\hline & $S_{4}$ & $\mathrm{G}$ & G & $\mathrm{VG}$ & $\mathrm{F}$ & $\mathrm{F}$ & G & $\mathrm{MG}$ & $\mathrm{G}$ & $\mathrm{MG}$ & $\mathrm{F}$ & $\mathrm{F}$ & $\mathrm{F}$ & G & $\mathrm{G}$ & $\mathrm{F}$ & $\mathrm{G}$ \\
\hline & $S_{5}$ & $\mathrm{VG}$ & $\mathrm{G}$ & G & MG & $\mathrm{F}$ & $\mathrm{MG}$ & G & G & G & $\mathrm{F}$ & MP & MG & MG & $\mathrm{VG}$ & $\mathrm{F}$ & $\mathrm{MG}$ \\
\hline & $S_{1}$ & $\mathrm{P}$ & VP & $\mathrm{F}$ & G & $\mathrm{F}$ & $\mathrm{G}$ & $\mathrm{VP}$ & MP & G & VP & $\mathrm{VG}$ & G & MP & G & $\mathrm{P}$ & $\mathrm{VG}$ \\
\hline & $S_{2}$ & MP & $\mathrm{VP}$ & $\mathrm{F}$ & $\mathrm{G}$ & $\mathrm{MG}$ & $\mathrm{VG}$ & VP & $\mathrm{P}$ & $\mathrm{G}$ & VP & $\mathrm{VG}$ & $\mathrm{G}$ & $\mathrm{P}$ & $\mathrm{G}$ & $\mathrm{P}$ & $\mathrm{G}$ \\
\hline \multirow[t]{3}{*}{$D_{5}$} & $S_{3}$ & MP & $\mathrm{P}$ & $\mathrm{MG}$ & $\mathrm{VG}$ & MG & $\mathrm{VG}$ & $\mathrm{VP}$ & $\mathrm{P}$ & $\mathrm{MG}$ & $\mathrm{VP}$ & $\mathrm{G}$ & $\mathrm{MG}$ & $\mathrm{P}$ & $\mathrm{VG}$ & $\mathrm{F}$ & $\mathrm{G}$ \\
\hline & $S_{4}$ & MP & $\mathrm{P}$ & $\mathrm{G}$ & $\mathrm{VG}$ & $F$ & $\mathrm{G}$ & $\mathrm{P}$ & $P$ & $\mathrm{MG}$ & $\mathrm{P}$ & $\mathrm{MG}$ & $\mathrm{F}$ & $\mathrm{F}$ & $\mathrm{MG}$ & MP & $\mathrm{MG}$ \\
\hline & $S_{5}$ & $\mathrm{P}$ & $\mathrm{P}$ & G & G & $\mathrm{F}$ & G & $P$ & MP & MG & MP & G & $\mathrm{F}$ & $\mathrm{F}$ & MG & $\mathrm{P}$ & VG \\
\hline
\end{tabular}


Table 4. Average fuzzy decision matrix

\begin{tabular}{cccccc}
\hline & $S_{1}$ & $S_{2}$ & $S_{3}$ & $S_{4}$ & $S_{5}$ \\
\hline$C_{11}$ & $(1,1.8,2.2,3.2)$ & $(4.4,5.4,5.8,6.8)$ & $(1,1.8,2.2,3.2)$ & $(7.6,8.6,9.2,9.6)$ & $(1.6,2.6,3.2,4.2)$ \\
\hline$C_{12}$ & $(5.8,6.8,7.4,8.4)$ & $(7.4,8.4,8.8,9.4)$ & $(4.2,5.2,5.4,6.4)$ & $(6.2,7.2,7.6,8.6)$ & $(0.60,1.2,1.6,2.6)$ \\
\hline$C_{13}$ & $(3.2,4.2,4.6,5.6)$ & $(3.2,4.2,4.6,5.6)$ & $(0.80,1.4,2,3)$ & $(7.6,8.6,9.2,9.6)$ & $(5.4,6.4,6.6,7.6)$ \\
\hline$C_{21}$ & $(7,8,8.6,9.2)$ & $(6.8,7.8,8.2,9)$ & $(5.4,6.4,6.6,7.6)$ & $(4.6,5.6,6.2,7.2)$ & $(7.4,8.4,8.8,9.4)$ \\
\hline$C_{22}(4.4,5.4,5.8,6.8)$ & $(5.8,6.8,7.4,8.4)$ & $(2,3,3.4,4.4)$ & $(3,4,4.2,5.2)$ & $(4.4,5.4,5.8,6.8)$ \\
\hline$C_{23}$ & $(5.6,6.6,7,8)$ & $(3.2,4.2,4.6,5.6)$ & $(0.40,0.80,1.4,2.4)$ & $(7,8,8.6,9.2)$ & $(7.4,8.4,8.8,9.4)$ \\
\hline$C_{24}$ & $(0.80,1.4,2,3)$ & $(1,1.6,2.4,3.4)$ & $(5,6,6.4,7.4)$ & $(5,6,6.4,7.4)$ & $(0.40,0.80,1.4,2.4)$ \\
\hline$C_{31}(2.8,3.8,4.4,5.4)$ & $(7.4,8.4,8.8,9.4)$ & $(3.2,4.2,4.6,5.6)$ & $(7.2,8.2,8.4,9.2)$ & $(1.4,2.4,2.8,3.8)$ \\
\hline$C_{32}(7.6,8.6,9.2,9.6)$ & $(7.6,8.6,9.2,9.6)$ & $(1.4,2.4,2.8,3.8)$ & $(6.4,7.4,8,8.8)$ & $(5.8,6.8,7.4,8.4)$ \\
\hline$C_{33}(6.2,7.2,7.6,8.6)$ & $(5.2,6.2,6.8,7.8)$ & $(4.6,5.6,6.2,7.2)$ & $(4.2,5.2,5.4,6.4)$ & $(0.60,1,1.8,2.8)$ \\
\hline$C_{34}(3.2,4.2,4.6,5.6)$ & $(4.4,5.4,5.8,6.8)$ & $(1.2,2,2.6,3.6)$ & $(3.2,4.2,4.6,5.6)$ & $(7,8,8.6,9.2)$ \\
\hline$C_{41}$ & $(4.6,5.6,6.2,7.2)$ & $(3.2,4.2,4.6,5.6)$ & $(3.8,4.8,5.2,6.2)$ & $(4.8,5.8,6,7)$ & $(5.4,6.4,6.6,7.6)$ \\
\hline$C_{42}(5.4,6.4,6.6,7.6)$ & $(6.4,7.4,8,8.8)$ & $(5,6,6.4,7.4)$ & $(5.4,6.4,6.6,7.6)$ & $(2.4,3.4,3.6,4.6)$ \\
\hline$C_{51}$ & $(2,3,3.4,4.4)$ & $(5.8,6.8,7.4,8.4)$ & $(2.6,3.6,4,5)$ & $(7.6,8.6,9.2,9.6)$ & $(6.4,7.4,8,8.8)$ \\
\hline$C_{52}$ & $(7,8,8.6,9.2)$ & $(1.4,2.4,2.8,3.8)$ & $(0.40,0.80,1.4,2.4)$ & $(3.2,4.2,4.6,5.6)$ & $(1.8,2.8,3,4)$ \\
\hline$C_{53}(6.8,7.8,8.2,8.8)$ & $(5,6,6.4,7.4)$ & $(4.4,5.4,5.8,6.8)$ & $(5.8,6.8,7.4,8.4)$ & $(7,8,8.6,9.2)$ \\
\hline
\end{tabular}

Table 5. Importance of the criteria and average fuzzy weights

\begin{tabular}{|c|c|c|c|c|c|c|c|}
\hline & & $D_{1}$ & $D_{2}$ & $D_{3}$ & $D_{4}$ & $D_{5}$ & Average \\
\hline \multirow{3}{*}{$C_{1}$} & $C_{11}$ & VL & $\mathrm{L}$ & $\mathrm{L}$ & ML & $\mathrm{L}$ & $(0.1,0.18,0.22,0.32)$ \\
\hline & $C_{12}$ & $\mathrm{H}$ & $\mathrm{MH}$ & $\mathrm{H}$ & $\mathrm{M}$ & $\mathrm{MH}$ & $(0.56,0.66,0.7,0.8)$ \\
\hline & $C_{13}$ & $\mathrm{VH}$ & $\mathrm{VH}$ & $\mathrm{VH}$ & $\mathrm{H}$ & $\mathrm{H}$ & $(0.76,0.86,0.92,0.96)$ \\
\hline \multirow{4}{*}{$C_{2}$} & $C_{21}$ & $M$ & MH & $\mathrm{M}$ & $M$ & MH & $(0.44,0.54,0.58,0.68)$ \\
\hline & $C_{22}$ & $\mathrm{VL}$ & ML & ML & $\mathrm{L}$ & $\mathrm{L}$ & $(0.12,0.2,0.26,0.36)$ \\
\hline & $C_{23}$ & $\mathrm{H}$ & $\mathrm{H}$ & $\mathrm{MH}$ & $\mathrm{H}$ & $\mathrm{MH}$ & $(0.62,0.72,0.76,0.86)$ \\
\hline & $C_{24}$ & $\mathrm{MH}$ & $\mathrm{M}$ & $\mathrm{M}$ & ML & $\mathrm{M}$ & $(0.38,0.48,0.52,0.62)$ \\
\hline \multirow{4}{*}{$C_{3}$} & $C_{31}$ & $\mathrm{~L}$ & ML & $\mathrm{L}$ & M & ML & $(0.2,0.3,0.34,0.44)$ \\
\hline & $C_{32}$ & M & M & MH & MH & MH & $(0.46,0.56,0.62,0.72)$ \\
\hline & $C_{33}$ & $\mathrm{VL}$ & $\mathrm{VL}$ & $\mathrm{L}$ & $\mathrm{VL}$ & $\mathrm{L}$ & $(0.04,0.08,0.14,0.24)$ \\
\hline & $C_{34}$ & $\mathrm{~L}$ & $\mathrm{~L}$ & $\mathrm{~L}$ & $\mathrm{VL}$ & $\mathrm{VL}$ & $(0.06,0.12,0.16,0.26)$ \\
\hline \multirow{2}{*}{$C_{4}$} & $C_{41}$ & $\mathrm{H}$ & $\mathrm{H}$ & $\mathrm{VH}$ & $\mathrm{VH}$ & $\mathrm{H}$ & $(0.74,0.84,0.88,0.94)$ \\
\hline & $C_{42}$ & $\mathrm{VH}$ & $\mathrm{H}$ & $\mathrm{H}$ & $\mathrm{MH}$ & $\mathrm{MH}$ & $(0.64,0.74,0.8,0.88)$ \\
\hline \multirow{3}{*}{$C_{5}$} & $C_{51}$ & ML & $\mathrm{M}$ & ML & $\mathrm{M}$ & $\mathrm{M}$ & $(0.32,0.42,0.46,0.56)$ \\
\hline & $C_{52}$ & $\mathrm{~L}$ & ML & $\mathrm{L}$ & ML & ML & $(0.16,0.26,0.32,0.42)$ \\
\hline & $C_{53}$ & $\mathrm{H}$ & $\mathrm{MH}$ & $\mathrm{M}$ & $\mathrm{MH}$ & $\mathrm{M}$ & $(0.5,0.6,0.64,0.74)$ \\
\hline
\end{tabular}


Step 2. The decision-makers evaluated the selected criteria and weighted them by using linguistic variables. Based on the evaluations of DMs and Eqs. (17) to (19), the average fuzzy weights are calculated. Table 5 presents the evaluation of decision-makers and average fuzzy weights of the criteria.

Steps 3 to 6. According to the results of Step 1 and Eqs. (20) and (21), the fuzzy normalized decision matrix can be determined. Then the average fuzzy weights of criteria (Table 5) and Eqs. (22) and (23) are utilized for calculating the fuzzy weighted normalized decision matrix. Afterwards, we need to compute the fuzzy negative-ideal solution based on Eqs (24) and (25). By using the elements of the fuzzy weighted normalized decision matrix, the fuzzy negative-ideal solution and Eqs. (26) and (27), we can calculate the fuzzy weighted Euclidean and fuzzy weighted Hamming distances of each alternative. The results of these steps are shown in Table 6.

Table 6. Fuzzy weighted normalized matrix, negative-ideal solution and distances

\begin{tabular}{|c|c|c|c|c|c|c|}
\hline & $S_{1}$ & $S_{2}$ & $S_{3}$ & $S_{4}$ & $S_{5}$ & $\widetilde{n s}_{j}$ \\
\hline$C_{11}$ & $(0.01,0.04,0.06,0.12)$ & $(0.05,0.11,0.15,0.25)$ & $(0.01,0.04,0.06,0.12)$ & $(0.09,0.18,0.23,0.35)$ & $(0.02,0.05,0.08,0.15)$ & $(0.01,0.04,0.06,0.12)$ \\
\hline$C_{12}$ & $(0.38,0.53,0.61,0.79)$ & $(0.49,0.65,0.73,0.89)$ & $(0.28,0.4,0.45,0.6)$ & $(0.41,0.56,0.63,0.81)$ & $(0.04,0.09,0.13,0.25)$ & $(0.04,0.09,0.13,0.25)$ \\
\hline$C_{13}$ & $(0.28,0.41,0.49,0.62)$ & $(0.28,0.41,0.49,0.62)$ & $(0.07,0.14,0.21,0.33)$ & $(0.66,0.85,0.97,1.06)$ & $(0.47,0.63,0.7,0.84)$ & $(0.07,0.14,0.21,0.33)$ \\
\hline$C_{21}$ & $(0.36,0.51,0.59,0.74)$ & $(0.35,0.5,0.56,0.72)$ & $(0.28,0.41,0.45,0.61)$ & $(0.24,0.36,0.42,0.58)$ & $(0.38,0.54,0.6,0.75)$ & $(0.24,0.36,0.42,0.58)$ \\
\hline$C_{22}$ & $(0.07,0.15,0.21,0.34)$ & $(0.1,0.19,0.27,0.43)$ & $(0.03,0.08,0.12,0.22)$ & $(0.05,0.11,0.15,0.26)$ & $(0.07,0.15,0.21,0.34)$ & $(0.03,0.08,0.12,0.22)$ \\
\hline$C_{23}$ & $(0.41,0.56,0.63,0.81)$ & $(0.23,0.36,0.41,0.57)$ & $(0.03,0.07,0.13,0.24)$ & $(0.51,0.68,0.77,0.93)$ & $(0.54,0.71,0.79,0.95)$ & $(0.03,0.07,0.13,0.24)$ \\
\hline$C_{24}$ & $(0.05,0.11,0.17,0.3)$ & $(0.06,0.12,0.2,0.34)$ & $(0.31,0.46,0.54,0.74)$ & $(0.31,0.46,0.54,0.74)$ & $(0.02,0.06,0.12,0.24)$ & $(0.02,0.06,0.12,0.24)$ \\
\hline$C_{31}$ & $(0.07,0.13,0.18,0.28)$ & $(0.17,0.3,0.35,0.49)$ & $(0.08,0.15,0.18,0.29)$ & $(0.17,0.29,0.34,0.48)$ & $(0.03,0.08,0.11,0.2)$ & $(0.03,0.08,0.11,0.2)$ \\
\hline$C_{32}$ & $(0.4,0.55,0.65,0.79)$ & $(0.4,0.55,0.65,0.79)$ & $(0.07,0.15,0.2,0.31)$ & $(0.34,0.48,0.57,0.73)$ & $(0.31,0.44,0.53,0.69)$ & $(0.07,0.15,0.2,0.31)$ \\
\hline$C_{33}$ & $(0.03,0.08,0.14,0.28)$ & $(0.03,0.07,0.13,0.25)$ & $(0.02,0.06,0.12,0.23)$ & $(0.02,0.06,0.1,0.21)$ & $(0,0.01,0.03,0.09)$ & $(0,0.01,0.03,0.09)$ \\
\hline$C_{34}$ & $(0.02,0.06,0.09,0.18)$ & $(0.03,0.08,0.11,0.22)$ & $(0.01,0.03,0.05,0.11)$ & $(0.02,0.06,0.09,0.18)$ & $(0.05,0.12,0.17,0.29)$ & $(0.01,0.03,0.05,0.11)$ \\
\hline$C_{41}$ & $(0.52,0.72,0.84,1.04)$ & $(0.36,0.54,0.62,0.81)$ & $(0.43,0.62,0.7,0.9)$ & $(0.55,0.75,0.81,1.01)$ & $(0.61,0.83,0.89,1.1)$ & $(0.36,0.54,0.62,0.81)$ \\
\hline$C_{42}$ & $(0.45,0.62,0.69,0.88)$ & $(0.54,0.72,0.84,1.01)$ & $(0.42,0.58,0.67,0.85)$ & $(0.45,0.62,0.69,0.88)$ & $(0.2,0.33,0.38,0.53)$ & $(0.2,0.33,0.38,0.53)$ \\
\hline$C_{51}$ & $(0.07,0.14,0.18,0.28)$ & $(0.21,0.33,0.39,0.54)$ & $(0.1,0.17,0.21,0.32)$ & $(0.28,0.41,0.49,0.62)$ & $(0.23,0.36,0.42,0.56)$ & $(0.07,0.14,0.18,0.28)$ \\
\hline$C_{52}$ & $(0.14,0.25,0.34,0.47)$ & $(0.03,0.08,0.11,0.2)$ & $(0.01,0.03,0.05,0.12)$ & $(0.06,0.13,0.18,0.29)$ & $(0.04,0.09,0.12,0.21)$ & $(0.01,0.03,0.05,0.12)$ \\
\hline$C_{53}$ & $(0.42,0.57,0.64,0.8)$ & $(0.31,0.44,0.5,0.67)$ & $(0.27,0.4,0.45,0.62)$ & $(0.35,0.5,0.58,0.76)$ & $(0.43,0.59,0.67,0.83)$ & $(0.27,0.4,0.45,0.62)$ \\
\hline$E D_{i}$ & 3.067 & 3.080 & 1.293 & 4.102 & 2.588 & \\
\hline$H D_{i}$ & 3.020 & 3.026 & 1.271 & 4.052 & 2.560 & \\
\hline
\end{tabular}

Steps 7 to 9. Based on Table 6 and Eqs. (28) to (30) the relative assessment matrix $(R A)$ is calculated. As previously mentioned, the value of $\theta$ in our computations is 0.02 . By using Eq. (31) and the elements of the relative assessment matrix, the assessment score of the alternatives can be calculated. Then the ranking of the alternatives is made based on decreasing values of the assessment scores. The results of these steps are represented in Table 7. According to Table 7, we can say that the market segment 4 is more appropriate than the other alternatives for investment. 
Table 7. Relative assessment matrix, appraisal scores and rank of the alternatives

\begin{tabular}{|c|c|c|c|c|c|c|c|c|c|}
\hline \multicolumn{6}{|c|}{$R A$} & \multirow[b]{2}{*}{$A S_{i}$} & \multicolumn{3}{|c|}{ Rank } \\
\hline & $S_{1}$ & $S_{2}$ & $S_{3}$ & $S_{4}$ & $S_{5}$ & & $\begin{array}{c}\text { Fuzzy } \\
\text { CODAS }\end{array}$ & $\begin{array}{l}\text { Fuzzy } \\
\text { EDAS }\end{array}$ & $\begin{array}{c}\text { Fuzzy } \\
\text { TOPSIS }\end{array}$ \\
\hline$S_{1}$ & 0 & -0.013 & 3.522 & -2.067 & 0.938 & 2.380 & 3 & 3 & 3 \\
\hline$S_{2}$ & 0.013 & 0 & 3.541 & -2.048 & 0.958 & 2.464 & 2 & 2 & 2 \\
\hline$S_{3}$ & -3.522 & -3.541 & 0 & -5.590 & -2.584 & -15.237 & 5 & 5 & 5 \\
\hline$S_{4}$ & 2.067 & 2.048 & 5.590 & 0 & 3.006 & 12.711 & 1 & 1 & 1 \\
\hline$S_{5}$ & -0.938 & -0.958 & 2.584 & -3.006 & 0 & -2.318 & 4 & 4 & 4 \\
\hline
\end{tabular}

To show the validity of the result, we compare it with the result of the fuzzy EDAS (Keshavarz Ghorabaee et al. 2016a) and fuzzy TOPSIS (Chen 2000; Roszkowska, Wachowicz 2015) methods. The results of the fuzzy EDAS and fuzzy TOPSIS methods are presented in the last two columns of Table 7. As can be seen, the ranking result of the fuzzy CODAS is completely consistent with the results of the fuzzy EDAS and fuzzy TOPSIS methods. A sensitivity analysis is also performed in this section to demonstrate the stability of the ranking result. Firstly, ten sets of criteria weights are generated randomly. Then we solve the problem by using each of these sets. The generated sets of criteria weights are shown in Table 8 and the ranking results are depicted in Figure 4.

Table 8 . Generated weights for sensitivity analysis

\begin{tabular}{lllllllllll}
\hline & Set 1 & Set 2 & Set 3 & Set 4 & Set 5 & Set 6 & Set 7 & Set 8 & Set 9 & Set 10 \\
\hline$C_{11}$ & 0.015 & 0.006 & 0.079 & 0.085 & 0.054 & 0.019 & 0.011 & 0.053 & 0.077 & 0.019 \\
\hline$C_{12}$ & 0.043 & 0.041 & 0.087 & 0.110 & 0.040 & 0.082 & 0.029 & 0.034 & 0.061 & 0.126 \\
\hline$C_{13}$ & 0.093 & 0.007 & 0.093 & 0.117 & 0.094 & 0.068 & 0.116 & 0.107 & 0.012 & 0.062 \\
\hline$C_{21}$ & 0.081 & 0.015 & 0.034 & 0.067 & 0.066 & 0.003 & 0.020 & 0.058 & 0.036 & 0.040 \\
\hline$C_{22}$ & 0.097 & 0.121 & 0.083 & 0.017 & 0.062 & 0.049 & 0.104 & 0.121 & 0.019 & 0.066 \\
\hline$C_{23}$ & 0.067 & 0.102 & 0.081 & 0.018 & 0.103 & 0.024 & 0.068 & 0.025 & 0.028 & 0.016 \\
\hline$C_{24}$ & 0.004 & 0.047 & 0.021 & 0.032 & 0.033 & 0.115 & 0.126 & 0.036 & 0.036 & 0.022 \\
\hline$C_{31}$ & 0.086 & 0.140 & 0.015 & 0.104 & 0.085 & 0.046 & 0.010 & 0.020 & 0.062 & 0.152 \\
\hline$C_{32}$ & 0.095 & 0.006 & 0.061 & 0.032 & 0.085 & 0.076 & 0.057 & 0.018 & 0.007 & 0.154 \\
\hline$C_{33}$ & 0.069 & 0.064 & 0.117 & 0.100 & 0.044 & 0.024 & 0.014 & 0.115 & 0.135 & 0.093 \\
\hline$C_{34}$ & 0.077 & 0.057 & 0.043 & 0.030 & 0.064 & 0.088 & 0.122 & 0.077 & 0.141 & 0.010 \\
\hline$C_{41}$ & 0.076 & 0.112 & 0.072 & 0.113 & 0.009 & 0.039 & 0.001 & 0.073 & 0.074 & 0.038 \\
\hline$C_{42}$ & 0.040 & 0.117 & 0.028 & 0.043 & 0.007 & 0.095 & 0.098 & 0.020 & 0.073 & 0.058 \\
\hline$C_{51}$ & 0.067 & 0.028 & 0.093 & 0.024 & 0.061 & 0.099 & 0.103 & 0.113 & 0.050 & 0.133 \\
\hline$C_{52}$ & 0.018 & 0.072 & 0.032 & 0.032 & 0.088 & 0.108 & 0.109 & 0.083 & 0.135 & 0.003 \\
\hline$C_{53}$ & 0.072 & 0.066 & 0.062 & 0.076 & 0.105 & 0.066 & 0.011 & 0.047 & 0.055 & 0.008 \\
\hline
\end{tabular}




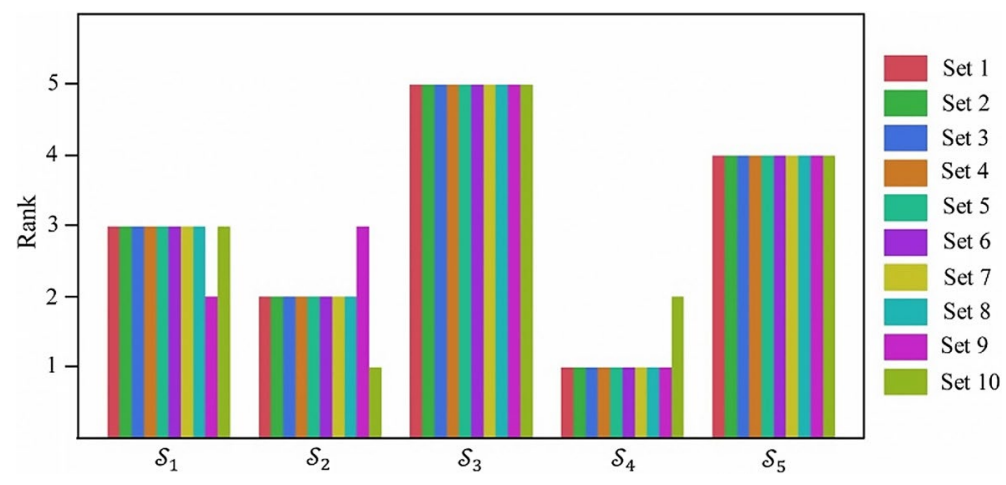

Fig. 4. Ranking results of the sensitivity analysis

According to Figure 4, the rank of the alternatives has a good stability against changing weights of the criteria. We can see that the market segment $4\left(S_{4}\right)$ is the dominant alternative in all sets except set 10 . Thus we can say that the initial ranking result is reliable.

\section{Discussion}

Uncertainty of information is usually an important issue to be dealt with in many MCDM problems like market segment evaluation and selection. The fuzzy sets theory is the most common tool to handle the uncertainty in such problems. In this study, we have proposed a fuzzy extension of the CODAS method based on the combination of fuzzy weighted Euclidean and fuzzy weighted Hamming distances. So far, most of the distance-based fuzzy MCDM methods have only used one type of distance in the evaluation process. The advantage of the proposed method over the other distance-based MCDM methods is its ability to involve two types of distance. Using two types of distance in evaluation process helps to increase the precision of ranking results. However, if the threshold parameter of the proposed method is set to a value more than a specific value related to the scale of problem (usually more than one), the proposed fuzzy CODAS will only utilize the fuzzy weighted Euclidean distance for evaluation process, and the fuzzy weighted Hamming distances will be ignored in computations. Unlike the other distance-based MCDM methods like TOPSIS and VIKOR, the evaluation process in the proposed fuzzy CODAS method is only based on negative-ideal solution, and the positive-ideal solution is not used in its process. To show the applicability of the proposed fuzzy CODAS method, a case study of market segment evaluation and selection has been considered. Sixteen sub-criteria related to five criteria, which have been defined according to the Porter's five forces model of competition, were selected by a group of five decision-makers (experts) of a shoe company to evaluate five market segments. Fuzzy linguistic variables have been used by decision-makers to express the importance (weight) of sub-criteria and the performance of alternatives with respect to each sub-criterion. Aggregating the assessments of the decision-makers about the importance of different sub-criteria has shown that "Buyer price sensitivity", "Buyer switching costs" and "Perceived level of product differentiation" were the first three 
important sub-criteria for the company to evaluate the market segments. The evaluation of alternatives has been done using the proposed fuzzy CODAS method and market segment $4\left(\mathcal{S}_{4}\right)$ has been presented as the best alternative. Then the obtained ranking of alternatives has been compared with the results of the fuzzy EDAS and fuzzy TOPSIS approaches to validate the results of the proposed method. This analysis shows that the results of the fuzzy CODAS method are completely consistent with the results of the other methods, and the market segment 4 has the first rank in the fuzzy EDAS and fuzzy TOPSIS results too. To examine the effect of changing criteria (sub-criteria) weights on the ranking results, a sensitivity analysis has also been made by using ten generated sets of sub-criteria weights. Although some minor changes in the ranking of alternatives have been seen in different sets of sub-criteria weights, the market segment 4 has the first rank in the most cases. Thus the company can select this alternative with high degree of reliability. Moreover, according to the comparison and sensitivity analysis, if the company wants to select another market, it can consider the market segment 2 as a secondary option.

\section{Conclusions}

Market segment evaluation and selection has a significant effect on the competitiveness of a company. Because this process can be viewed as a multi-criteria decision-making problem, we usually need to use an efficient MCDM method for it. Moreover, uncertain environment of decision-making process can make this evaluation complicated. In this research, we have developed an extension of fuzzy CODAS method to deal with MCDM problems under uncertainty. We have used the fuzzy weighted Euclidean and fuzzy weighted Hamming distances to determine the desirability of alternatives with respect to a negative-ideal solution. Also, the linguistic variables which are defined by trapezoidal fuzzy numbers have been used to extend the crisp CODAS method. The proposed fuzzy CODAS method has been applied to an example of multi-criteria market segment evaluation and selection problem. The comparative analysis of evaluation results shows that the fuzzy CODAS method is efficient and consistent with the other methods, and the sensitivity analysis demonstrates the stability of the results of the proposed method. Because the interdependency of criteria is not considered in the proposed method, one of the limitations of this research can be choosing or defining independent criteria for evaluation and selection process. Future research can address the interdependency of criteria by using some usual methods like fuzzy analytic network process (ANP). Moreover, the proposed method can be applied to many other MCDM problems such as supplier selection, project selection, robot selection.

\section{References}

Aghdaie, M. H.; Alimardani, M. 2015. Target market selection based on market segment evaluation: a multiple attribute decision making approach, International Journal of Operational Research 24(3): 262-278. https://doi.org/10.1504/IJOR.2015.072231

Aliakbari Nouri, F.; Khalili Esbouei, S.; Antucheviciene, J. 2015. A hybrid MCDM approach based on fuzzy ANP and fuzzy TOPSIS for technology selection, Informatica 26(3): 369-388. https://doi.org/10.15388/Informatica.2015.53 
Barić, D.; Pilko, H.; Strujić, J. 2016. An analytic hierarchy process model to evaluate road section design, Transport 31(3): 312-321. https://doi.org/10.3846/16484142.2016.1157830

Camargo Pérez, J.; Carrillo, M. H.; Montoya-Torres, J. R. 2015. Multi-criteria approaches for urban passenger transport systems: a literature review, Annals of Operations Research 226(1): 69-87. https://doi.org/10.1007/s10479-014-1681-8

Chang, D.-Y. 1996. Applications of the extent analysis method on fuzzy AHP, European Journal of Operational Research 95(3): 649-655. https://doi.org/10.1016/0377-2217(95)00300-2

Chen, S.-J.; Hwang, C.-L. 1992. Fuzzy multiple attribute decision making: methods and applications. Springer Berlin Heidelberg. https://doi.org/10.1007/978-3-642-46768-4

Chen, C.-T. 2000. Extensions of the TOPSIS for group decision-making under fuzzy environment, Fuzzy Sets and Systems 114(1): 1-9. https://doi.org/10.1016/S0165-0114(97)00377-1

Dat, L. Q.; Phuong, T. T.; Kao, H.-P.; Chou, S.-Y.; Nghia, P. V. 2015. A new integrated fuzzy QFD approach for market segments evaluation and selection, Applied Mathematical Modelling 39(13): 3653-3665. https://doi.org/10.1016/j.apm.2014.11.051

Dibb, S.; Simkin, L. 2008. Market segmentation success: making it happen! Routledge.

Ebrahimi, M.; Mirzayi Modam, M. 2016. Selecting the best zones to add new emergency services based on a hybrid fuzzy MADM method: a case study for Tehran, Safety Science 85: 67-76. https://doi.org/10.1016/j.ssci.2015.10.011

Hashemkhani Zolfani, S.; Sedaghat, M.; Maknoon, R.; Zavadskas, E. K. 2015. Sustainable tourism: a comprehensive literature review on frameworks and applications, Economic ResearchEkonomska Istraživanja 28(1): 1-30. https://doi.org/10.1080/1331677X.2014.995895

Hosseini, S. T.; Lale Arefi, S.; Bitarafan, M.; Abazarlou, S.; Zavadskas, E. K. 2016. Evaluation types of exterior walls to reconstruct Iran earthquake areas (Ahar Heris Varzeqan) by using AHP and fuzzy methods, International Journal of Strategic Property Management 20(3): 328-340. https://doi.org/10.3846/1648715X.2016.1190794

Kahraman, C.; Onar, S. C.; Oztaysi, B. 2015. Fuzzy multicriteria decision-making: a literature review, International Journal of Computational Intelligence Systems 8(4): 637-666.

https://doi.org/10.1080/18756891.2015.1046325

Keshavarz Ghorabaee, M.; Zavadskas, E. K.; Olfat, L.; Turskis, Z. 2015. Multi-criteria inventory classification using a new method of evaluation based on distance from average solution (EDAS), Informatica 26(3): 435-451. https://doi.org/10.15388/Informatica.2015.57

Keshavarz Ghorabaee, M.; Zavadskas, E. K.; Amiri, M.; Turskis, Z. 2016a. Extended EDAS method for fuzzy multi-criteria decision-making: an application to supplier selection, International Journal of Computers Communications \& Control 11(3): 358-371.

https://doi.org/10.15837/ijccc.2016.3.2557

Keshavarz Ghorabaee, M.; Zavadskas, E. K.; Turskis, Z.; Antucheviciene, J. 2016b. A new combinative distance-based assessment (CODAS) method for multi-criteria decision-making, Economic Computation \& Economic Cybernetics Studies \& Research 50(3): 25-44.

Khandekar, A. V.; Chakraborty, S. 2015. Selection of material handling equipment using fuzzy axiomatic design principles, Informatica 26(2): 259-282.

https://doi.org/10.15388/Informatica.2015.48

Kouchaksaraei, R. H.; Hashemkhani Zolfani, S.; Golabchi, M. 2015. Glasshouse locating based on SWARA-COPRAS approach, International Journal of Strategic Property Management 19(2): 111-122. https://doi.org/10.3846/1648715X.2015.1004565

Lamb, C. W.; Hair, J. F.; Mcdaniel, C. 2011. Essentials of marketing. Cengage Learning.

Li, D.-F. 2007. Compromise ratio method for fuzzy multi-attribute group decision making, Applied Soft Computing 7(3): 807-817. https://doi.org/10.1016/j.asoc.2006.02.003 
Mardani, A.; Jusoh, A.; Md Nor, K.; Khalifah, Z.; Zakwan, N.; Valipour, A. 2015. Multiple criteria decision-making techniques and their applications - a review of the literature from 2000 to 2014, Economic Research-Ekonomska Istraživanja 28(1): 516-571.

https://doi.org/10.1080/1331677X.2015.1075139

Mardani, A.; Zavadskas, E. K.; Khalifah, Z.; Jusoh, A.; Nor, K. M. D. 2016. Multiple criteria decision-making techniques in transportation systems: a systematic review of the state of the art literature, Transport 31(3): 359-385. https://doi.org/10.3846/16484142.2015.1121517

Mohammadi Nasrabadi, A.; Hosseinpour, M. H.; Ebrahimnejad, S. 2013. Strategy-aligned fuzzy approach for market segment evaluation and selection: a modular decision support system by dynamic network process (DNP), Journal of Industrial Engineering International 9(1): 1-17. https://doi.org/10.1186/2251-712X-9-11

Montoya-Weiss, M.; Calantone, R. J. 1999. Development and implementation of a segment selection procedure for industrial product markets, Marketing Science 18(3): 373-395.

https://doi.org/10.1287/mksc.18.3.373

Ölçer, A. İ.; Odabaşi, A.Y. 2005. A new fuzzy multiple attributive group decision making methodology and its application to propulsion/manoeuvring system selection problem, European Journal of Operational Research 166(1): 93-114. https://doi.org/10.1016/j.ejor.2004.02.010

Ou, C.-W.; Chou, S.-Y.; Chang, Y.-H. 2009. Using a strategy-aligned fuzzy competitive analysis approach for market segment evaluation and selection, Expert Systems with Applications 36(1): 527-541. https://doi.org/10.1016/j.eswa.2007.09.018

Porter, M. E. 1979. How competitive forces shape strategy, Harvard Business Review 57(2): 137-145.

Porter, M. E. 2008. Competitive strategy: techniques for analyzing industries and competitors. Simon and Schuster.

Ranjan, R.; Chatterjee, P.; Chakraborty, S. 2016. Performance evaluation of Indian states in tourism using an integrated PROMETHEE-GAIA approach, OPSEARCH 53(1): 63-84.

https://doi.org/10.1007/s12597-015-0225-6

Roszkowska, E.; Wachowicz, T. 2015. Application of fuzzy TOPSIS to scoring the negotiation offers in ill-structured negotiation problems, European Journal of Operational Research 242(3): 920-932. https://doi.org/10.1016/j.ejor.2014.10.050

Shahryari Nia, A.; Olfat, L.; Esmaeili, A.; Rostamzadeh, R.; Antuchevičienė, J. 2016. Using fuzzy Choquet Integral operator for supplier selection with environmental considerations, Journal of Business Economics and Management 17(4): 503-526.

https://doi.org/10.3846/16111699.2016.1194315

Shen, K.-Y.; Tzeng, G.-H. 2016. Combining DRSA decision-rules with FCA-based DANP evaluation for financial performance improvements, Technological and Economic Development of Economy 22(5): 685-714. https://doi.org/10.3846/20294913.2015.1071295

Vinodh, S.; Sai Balagi, T. S.; Patil, A. 2016. A hybrid MCDM approach for agile concept selection using fuzzy DEMATEL, fuzzy ANP and fuzzy TOPSIS, The International Journal of Advanced Manufacturing Technology 83(9): 1979-1987. https://doi.org/10.1007/s00170-015-7718-6

Wang, T.; Chang, T. 2005. Fuzzy VIKOR as a resolution for multicriteria group decision-making, in 11th International Conference on Industrial Engineering and Engineering Management, 12 April 2005, Shenyang, China, 352-356.

Wang, Y.-J.; Lee, H.-S. 2007. Generalizing TOPSIS for fuzzy multiple-criteria group decisionmaking, Computers \& Mathematics with Applications 53(11): 1762-1772.

https://doi.org/10.1016/j.camwa.2006.08.037

Wang, Y.-M.; Yang, J.-B.; Xu, D.-L.; Chin, K.-S. 2006. On the centroids of fuzzy numbers, Fuzzy Sets and Systems 157(7): 919-926. https://doi.org/10.1016/j.fss.2005.11.006

Wedel, M.; Kamakura, W. A., 2012. Market segmentation: conceptual and methodological foundations. Springer Science \& Business Media. 
Wind, Y.; Thomas, R. J. 1994. Segmenting industrial markets, Advance in Business Marketing and Purchasing 6: 59-82.

Zadeh, L. A. 1965. Fuzzy sets, Information and Control 8(3): 338-353.

https://doi.org/10.1016/S0019-9958(65)90241-X

Zavadskas, E. K.; Mardani, A.; Turskis, Z.; Jusoh, A.; Nor, K. M. 2016. Development of TOPSIS method to solve complicated decision-making problems: an overview on developments from 2000 to 2015, International Journal of Information Technology \& Decision Making 15(3): 645682. https://doi.org/10.1142/S0219622016300019

Zimmermann, H. J. 2010. Fuzzy set theory, Wiley Interdisciplinary Reviews: Computational Statistics 2(3): 317-332. https://doi.org/10.1002/wics.82

Mehdi KESHAVARZ GHORABAEE received the B.S. degree in electrical engineering from University of Guilan, Rasht, Iran in 2010 and the M.S. degree in production management from Allameh Tabataba'i University, Tehran, Iran in 2013. He is currently working toward the PhD degree in Operations Research at Allameh Tabataba'i University. He has published some papers in leading international journals such as Robotics and Computer-Integrated Manufacturing, The International Journal of Advanced Manufacturing Technology, Journal of Cleaner Production and Applied Mathematical Modelling. His research interests include multi-criteria decision making (MCDM), multi-objective evolutionary algorithms, genetic algorithm, fuzzy MCDM, inventory control, supply chain management, scheduling and reliability engineering.

Maghsoud AMIRI is Professor at the Department of Industrial Management, Allame Tabataba'i University, Tehran, Iran. He received $\mathrm{PhD}$ degree in industrial engineering from Sharif University of Technology, Tehran, Iran. He has published many papers in leading international journals. His research interests include multi-criteria decision-making (MCDM), data envelopment analysis (DEA), design of experiments (DOE), response surface methodology (RSM), fuzzy MCDM, inventory control, supply chain management, simulation and reliability engineering.

Edmundas Kazimieras ZAVADSKAS is Professor, Head of the Department of Construction Technology and Management at Vilnius Gediminas Technical University, Vilnius, Lithuania, and a chief researcher at Research Institute of Smart Building Technologies. He has a PhD in building structures (1973) and DrSc (1987) in building technology and management. He is a member of the Lithuanian and several foreign Academies of Sciences. He is Doctor Honoris Causa at Poznan, Saint-Petersburg, and Kiev universities. He is Editor-in-Chief and a member of editorial boards of a number of research journals. He is author and co-author of more than 500 papers and a number of monographs. His research interests include building technology and management, multi-criteria decision-making (MCDM) theory, automation in design and decision support systems.

Reyhaneh HOOSHMAND received the B.A. degree in business management from Allameh Tabataba'i University, Tehran, Iran in 2016. She was identified as an exceptionally talented student from the department of business management of Allameh Tabataba'i University, and has been granted a permission to study for master degree without the entrance exam. She is currently working toward the master degree in strategic management at Allameh Tabataba'i University. Her research interests include strategic planning, market research, multi-criteria decision-making, marketing and strategy development.

Jurgita ANTUCHEVIČIENE் is Professor at the Department of Construction Technology and Management at Vilnius Gediminas Technical University, Vilnius, Lithuania. She received a PhD in civil engineering at Vilnius Gediminas Technical University in 2005. She is author and co-author of about 80 scientific papers. Her research interests include multi-criteria decision-making (MCDM), fuzzy MCDM, decision support systems, sustainable development, construction management and investment. 